\title{
HUMIFICAÇÃO E MINERALIZAÇÃO DE MACRÓFITAS AQUÁTICAS: UMA REVISÃO SOBRE ESSES PROCESSOS
}

\author{
Marcela B. Cunha-Santino ${ }^{1} \&$ Irineu Bianchini Jr. ${ }^{1}$ \\ ${ }^{1}$ Departamento de Hidrobiologia, Universidade Federal de São Carlos. Rodovia Washington Luiz, km 235. Caixa Postal 676. São Paulo, Brasil. \\ CEP: 13565-905. \\ E-mails: cunha_santino@ufscar.br,irineu@ufscar.br
}

\section{RESUMO}

A decomposição das macrófitas aquáticas resulta em biomassa de microorganismos, água, sais minerais, gases e compostos húmicos. As substâncias húmicas representadas pelos ácidos húmicos e fúlvicos são caracterizadas como sendo um material de alta massa molecular, polar, amorfo, de natureza heterogênea e com diferentes graus de polimerização. Nos ecossistemas aquáticos, essas substâncias fazem parte do reservatório de carbono orgânico (dissolvido e particulado) apresentando tanto papel ecológico quanto fisiológico. No processo de formação dos compostos húmicos (humificação) dos detritos de plantas aquáticas verificouse o predomínio de SH na matéria orgânica particulada em relação à dissolvida, sendo o ácido fúlvico o principal constituinte. Embora as substâncias húmicas apresentem características recalcitrantes em relação à biodegradação, a mineralização desses compostos é essencial para a circulação do húmus e fundamental para a manutenção do ciclo global do carbono. A refratabilidade desses compostos faz com que eles sejam degradados lentamente no ambiente aquático; desse modo, grande parte das substâncias húmicas incorpora-se no sedimento. Os processos de mineralização e de humificação são concorrentes e apresentam rendimentos distintos em função das condições ambientais predominantes.

Palavras-chave: Substâncias húmicas, decomposição, ciclagem, matéria orgânica dissolvida e particulada.

\begin{abstract}
HUMIFICATION AND MINERALIZATION OF AQUATIC MACROPHYTES: A REWIEW. The decomposition of aquatic macrophytes results in the production of an amount of microorganisms, water, minerals, gases and humic compounds. Humic compounds are humic and fulvic acids which are polar substances with elevated molecular mass and irregular appearance, of heterogeneous nature and with varied degrees of polymerization. In aquatic ecosystems these substances take part in the pool of dissolved and particulate organic carbon, thus they hold considerable ecological and physiological importance. In the process of formation of humic compounds (humification) from the detritus of aquatic plants, a relative predominance of SH in the particulate organic matter in comparison to dissolved organic matter is perceived, with fulvic acid being the predominant compound. Although humic substances present recalcitrant properties in biodegradation, mineralization of these substances is essential in humus cycling and in the global carbon cycle. The refractance index of these substances renders them slow to decay in natural conditions, thus sediments acquire a great amount of humic substances. The processes of mineralization and humification can thus be seen as antagonist processes that evolve at different rates according with ambient conditions.
\end{abstract}

Key-words: Humic substances, decomposition, nutrient cycling, dissolved and particulate organic matter.

\section{RESUMEN}

HUMIFICACIÓN Y MINERALIZACIÓN DE MACRÓFITAS ACUÁTICAS: UNA REVISIÓN. La descomposición de las macrófitas acuáticas, da como resultado biomasa de microorganismos, agua, sales 
minerales, gases y compuestos húmicos. Las sustancias húmicas representadas por los ácidos húmicos y fúlvicos, constituyen un material de alta masa molecular, polar, amorfo, de naturaleza heterogénea y con diferente grado de polimerización. En los sistemas acuáticos, estas sustancias son parte del reservorio de carbono orgánico (disuelto y particulado) cumpliendo un rol ecológico y fisiológico. En el proceso de formación de compuestos húmicos (humificación) a partir de los detritus de plantas acuáticas se verificó el predominio de SH en la materia orgánica particulada en relación a la disuelta, siendo el ácido fúlvico el principal constituyente. Aunque las sustancias húmicas presenten características recalcitrantes en relación a la biodegradación, la mineralización de estos compuestos es esencial para la circulación de humus y es fundamental para el mantenimiento del ciclo global del carbono. La refractabilidad de estos compuestos hace que ellos sean degradados lentamente en el ambiente acuático, por lo que gran parte de las sustancias húmicas se incorporan al sedimento. Los procesos de mineralización y de humificación son competidores y presentan rendimientos distintos en función de las condiciones ambientales predominantes.

Palabras clave: Sustancias húmicas, descomposición, ciclo biogeoquímico, materia orgánica disuelta y particulada.

\section{MACRÓFITAS AQUÁTICAS COMO FONTE DE DETRITOS}

As zonas litorâneas dos ambientes lacustres constituem as interfaces entre os ambientes terrestres e aquáticos; essas regiões são usualmente colonizadas por diferentes espécies de macrófitas aquáticas. Essas plantas representam um componente importante da biota desses sistemas apresentando, geralmente, uma produtividade elevada (Raspopov et al. 2002). Após a senectude das macrófitas grandes quantidades de biomassa são aduzidas na cadeia de detritos tanto na forma de matéria orgânica particulada (MOP) quanto dissolvida (MOD). Na comparação entre as frações orgânicas dos ecossistemas aquáticos naturais, tem sido constatado um predomínio das frações dissolvidas sobre as particuladas (Steinberg 2003).

Durante a decomposição, as transformações bioquímicas que ocorrem no detrito vegetal através do metabolismo microheterótrofo são fundamentais para a dinâmica dos ciclos de nutrientes e do fluxo de energia dos ecossistemas aquáticos. A conversão do tecido vascular das plantas aquáticas (MOP) em MOD é de extrema importância do ponto de vista ecológico, uma vez que essas plantas fornecem carbono e nutrientes para a microbiota presente na coluna de água e para os microrganismos aderidos na MOP (Anesio et al. 2003). O processo degradativo pode ser efetuado em meio aeróbio ou anaeróbio; nesse contexto, os principais produtos da decomposição aeróbia são: dióxido de carbono, água, biomassa de microorganismos e compostos húmicos. $\mathrm{Na}$ ausência de oxigênio, o carbono orgânico é metabolizado incompletamente, acumulando-se na forma de substâncias intermediárias como acetato, etanol, lactato e succinato. Nesta condição, em geral, são produzidas grandes quantidades de metano e pequenas quantidades de hidrogênio. É comum, ainda, a formação de nitrogênio molecular, gás sulfídrico e mercaptanos (Megonigal et al. 2004). Sendo assim, no longo prazo, a decomposição resulta na conversão dos produtos orgânicos em produtos inorgânicos (mineralização), tais produtos serão novamente utilizados nos processos de produção primária, completando o ciclo biogeoquímico.

\section{DETRITOS PARTICULADOS E DISSOLVIDOS E AS SUBSTÂNCIAS HÚMICAS}

A MOD pode ser definida como a fração da matéria orgânica que pode ser filtrada em tamanho de poro menor que $0,45 \mu \mathrm{m}$ (Rand et al. 1995), na sua composição incluem-se desde pequenas moléculas orgânicas a grandes compostos poliméricos húmicos (substâncias húmicas - $\mathrm{SH}$ ) com massas moleculares variando de 100 a $100.000 \mathrm{Da}$ (Aitkenhead-Peterson et al. 2003). Nos ambientes aquáticos a MOD pode ser diferenciada em duas categorias: (i) lábil e (ii) refratária (Tulonen 2004, Gruber et al. 2006). A fração lábil tem sua origem nos produtores primários autóctones (fitoplâncton e macrófitas aquáticas), sendo liberada nos primeiros estágios da degradação das plantas aquáticas (lixiviação) e se constituí usualmente de compostos orgânicos simples e de grande valor energético (Ochiai et al. 1980). A maior parte da MOD lábil é assimilada prontamente pelas 
bactérias passando a representar a fração particulada na forma de biomassa microbiana viva (Mann \& Wetzel 1996, Faria \& Esteves 2001). Entretanto, a MOD proveniente de fontes alóctones é, geralmente, considerada refratária uma vez que foi anteriormente exposta à degradação e transformação microbiana antes de atingir o ambiente aquático (Wetzel 2001).

A MOD pode interagir com a biota por cinco diferentes maneiras: (i) fornecendo energia ou carbono orgânico para bactérias e algas (Purvina et al. 2008), (ii) apresentando-se como fator acessório de crescimento (ex. vitaminas; Münster et al. 1999), (ii) exercendo efeito tóxico em algas (Gross 2003), (iv) formando complexos orgânicos com elementos traços, que podem ter efeito benéfico ou não sobre os organismos (Tranvik 1994) e (v) absorvendo luz e, portanto, afetando os processos fotossintéticos (Lindell et al. 1995).

$\mathrm{Na}$ composição química da MOD, incluise o carbono orgânico dissolvido, com relação à procedência das formas de carbono, usualmente têm sido observadas nos ambientes aquáticos, cinco fontes principais: (i) compostos orgânicos de origem alóctone (Tranvik 1992); (ii) material orgânico originado da decomposição dos organismos aquáticos (CunhaSantino \& Bianchini Jr. 2008); (iii) metabólitos extracelulares ou fotossintetisados excretados pelo fitoplâncton (Krevs et al. 2007); (iv) metabólitos extracelulares ou fotossintetisados excretados pelas macrófitas aquáticas da zona litoral (Mulderij et al. 2007) e (v) excreção da fauna (Fernandez-Jover et al. 2007). A matéria orgânica detrital que entra nos sistemas aquáticos pode ser utilizada nas formas de carbono orgânico dissolvido (COD) e carbono orgânico particulado (COP). A concentração de COD em ambientes aquáticos continentais pode variar de 0,5 a $50 \mathrm{mg} \mathrm{L}^{-1}$ (Steinberg 2003). O COD varia de acordo com a produtividade do lago, apresentando tendência ao aumento em relação ao estado trófico do ambiente. As bactérias são as principais responsáveis pelas ciclagens de COD nos sistemas aquáticos; esse fato pode ser atribuído ao elevado número de microorganismos e a versatilidade metabólica desses organismos.

Quantitativamente, a MOP e a MOD nas águas naturais são constituídas por frações significativas de SH (Jackson 1989). Considerando as águas naturais, de 30 a $50 \%$ do COD é representado por substâncias húmicas, esse valor pode ser > 50\% para lagos pantanosos e de turfeiras (Rand et al. 1995). As SH aquáticas podem ser originadas do húmus do solo adjacentes aos corpos d'água, de material degradado das plantas vasculares de origem autóctone (macrófitas aquáticas e algas) e alóctone (Thurman 1985). As primeiras teorias descreviam as $\mathrm{SH}$ como produtos poliméricos derivados da degradação de carboidratos, ligninas, proteínas e gorduras em diferentes estágios de decomposição (Stevenson 1982), ou seja, as moléculas complexas grandes de substâncias húmicas ocorrem a partir de condensações e/ou polimerizações (enzimáticas e/ ou químicas) de produtos relativamente simples da decomposição (Golterman 1975, Swift et al. 1979). Uma teoria recente sugere que em vez de serem polímeros macromoleculares, as SH são associações supramoleculares de moléculas heterogêneas, unidas por ligações fracas adjacentes a sítios hidrofóbicos e hidrofílicos de grandes moléculas (Picollo et al. 2000).

A estrutura molecular das SH ainda não foi definida, porém, de modo geral, a seguinte composição elementar (em termos de peso seco) tem sido proposta: C: 50 a $60 \%$; O: 30 a $40 \%$; H: 4 a $5 \%$; N: 1 a 5\% (Thurman 1985). A análise elementar das substâncias húmicas da água de 16 lagos da Latvia indicaram a seguinte composição química: $49,38 \%$ a $58,34 \%$ de $\mathrm{C}, 3,68 \%$ a $4,72 \%$ de $\mathrm{H}, 0,61 \%$ a $2,64 \%$ de $\mathrm{N}$ e $32,67 \%$ a $45,34 \%$ de $\mathrm{O}$ (Klavins et al. 2003). Esses compostos não apresentam evidências de cristalinidade e de padrões de repetições de ligações ou de constituintes monoméricos (Swift et al. 1979). As SH são caracterizadas como sendo um material de massa molecular alta (Tate 1995), polar, amorfo de natureza heterogênea, polifuncional, com diferentes graus de polimerização (Hurst \& Burges 1967, Saunders 1980). Apresentam coloração amarelada a marrom (Thurmam \& Malcolm 1981). As SH apresentam tanto papel ecológico quanto fisiológico nos ecossistemas aquáticos (Steinberg 2003).

De forma geral as $\mathrm{SH}$ podem ser diferenciadas em três grandes categorias: ácido húmico $(\mathrm{AH})$, ácido fúlvico (AF) e humina (HU). Estas frações podem ser obtidas através de extração alcalina (GarnierSillam et al. 1999, Steinberg 2003). A acidificação do extrato alcalino resulta na precipitação do $\mathrm{AH}$. O AF é solúvel em álcali e em ácido. A HU é a porção 
da matéria orgânica coloidal que não é solúvel tanto em ácido quanto em álcali (Figura 1). A Sociedade Internacional de Substâncias Húmicas (International Humic Substance Society - IHSS) considera as SH como o material adsorvido em resina hidrofóbica (resinas-XAD). O AH é um composto sólido, cuja coloração varia do marrom ao preto, dependendo de seu grau de polimerização e apresenta pouca solubilidade em água. Na molécula de $\mathrm{AH}$ uma série de grupos funcionais pode ser reconhecida, desta forma estes grupos fornecem suas características aos compostos húmicos. Entre estes grupos funcionais citam-se: carboxilas, metoxilas, fenóis, quinonas, cetonas e alquenos. Anéis aromáticos, açúcares e aminoácidos também estão presentes. Na presença de grupos carboxilas e fenóis, os ácidos húmicos atuam como trocadores de cátions, e assim formam complexos quelados com metais (Golterman 1975). O AF é uma substância sólida que apresenta coloração que se estende do amarelo ao alaranjado escuro
(Toledo 1976) apresentando massa molecular mais baixa que o $\mathrm{AH}$.

\section{HUMIFICAÇÃO DE PLANTAS AQUÁTICAS}

Poucos estudos enfocaram a formação de húmus (humificação) desde a degradação de plantas aquáticas; as espécies estudadas foram Nymphoides indica (decomposição anaeróbia; Bianchini Jr. 1985), Mayaca fluviatilis (decomposição anaeróbia; D’Arienzo, 1989) Scirpus cubensis, Cabomba piauhyensis e Salvinia auriculata (decomposição anaeróbia; Campos Jr. 1998), Scirpus cubensis e Cabomba piauhyensis (decomposição aeróbia; Cunha \& Bianchini Jr. 2001), Egeria najas e Eichhornia azurea (decomposição anaeróbia; Bitar 2003).

$\mathrm{O}$ rendimento da humificação (ácidos fúlvico e húmico) em 68 dias de degradação aeróbia da MOP de Scirpus cubensis foi $95 \%$ de AF e 5\% de AH. O lixiviado (MOD) gerado nesse processo produziu

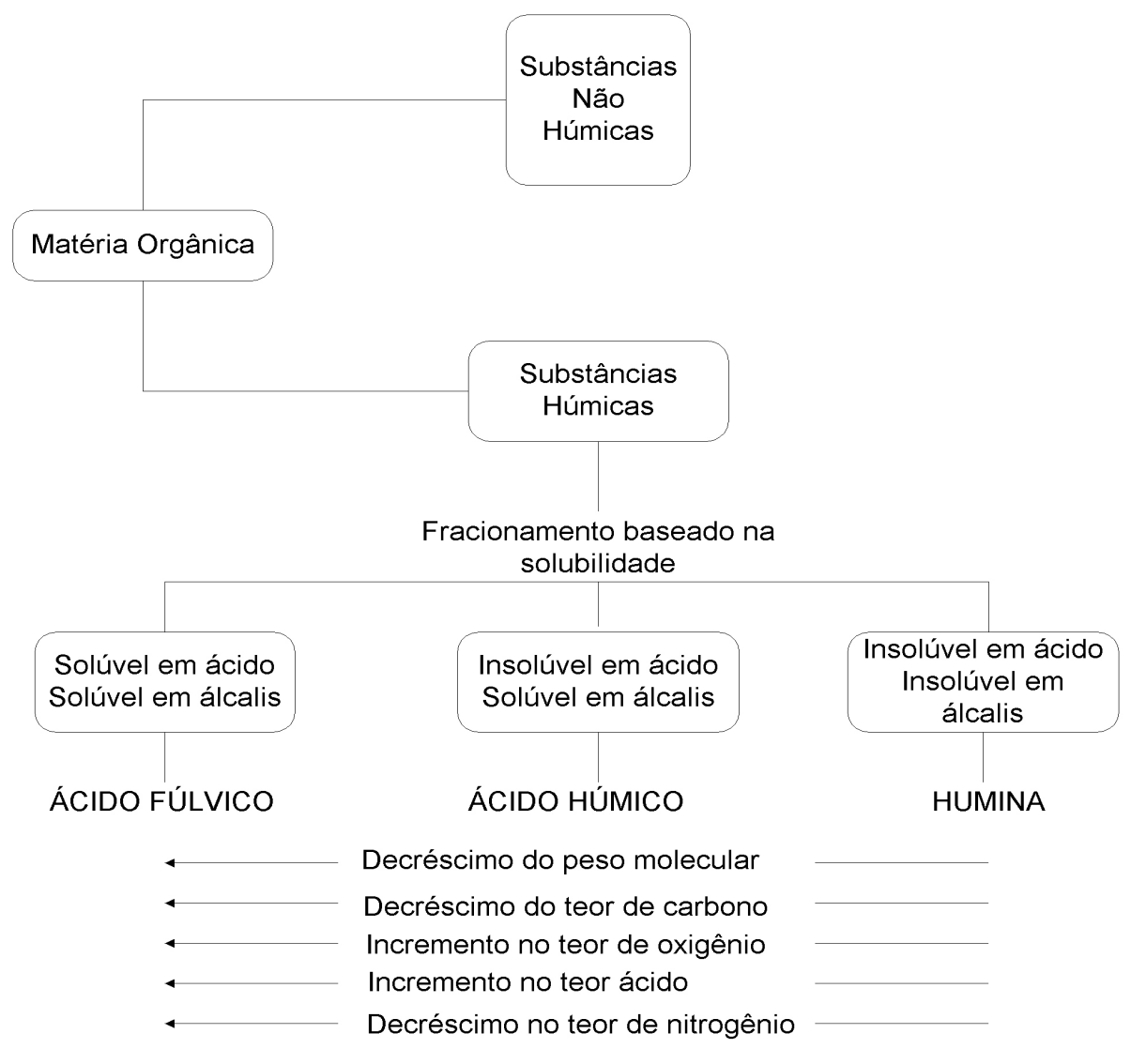

Figura 1. Diagrama esquemático do fracionamento da matéria orgânica detrital e algumas variações das propriedades entre os ácidos fúlvicos, húmicos e humina (modificado de Hayes \& Swift 1978).

Figure 1. Diagram illustrating fractioning of organic debris and variations in the properties of fulvic and humic acids, and humine. Adapted from Hayes \& Swift 1978. 
$78 \%$ de $\mathrm{AF}$ e $22 \%$ de $\mathrm{AH}$ (Cunha \& Bianchini Jr. 1994). Após 120 dias de degradação aeróbia de Scirpus cubensis e Cabomba piauhyensis coletadas em uma lagoa marginal do rio Mogi-Guaçu observouse para essas espécies de macrófitas aquáticas, a predominância da contribuição da MOP no processo de humificação (Figuras 2A e 2B). Os AF foram os principais constituintes nas composições das $\mathrm{SH}$ de ambas as espécies de macrófitas aquáticas, tanto das frações dissolvidas quanto das particuladas (Figuras $2 \mathrm{C}$ e 2D). Esta predominância provavelmente esteja relacionada com o fato de o AF ser um suposto precursor do $\mathrm{AH}$.

$\mathrm{Na}$ humificação de $N$. indica (120 dias de degradação em condições anaeróbias) houve o predomínio de $\mathrm{SH}$ formadas a partir da MOD (Bianchini Jr. 1985). Durante 120 dias de decomposição anaeróbia sob diferentes atmosferas (hidrogênio e nitrogênio) foram obtidos os seguintes rendimentos médios de $\mathrm{SH}_{\text {totais }}: 13,3 \%$ para Salvinia auriculata, 8,6\% para Scirpus cubensis e 7,9\% para Cabomba piauhyensis (Campos Jr. 1998). O mesmo autor realizou incubações com litterbags na lagoa do Infernão (E. E. de Jataí, Luiz Antonio, SP) com S. cubensis e $S$. auriculata e obteve os respectivos rendimentos para $\mathrm{SH}_{\text {totais }} 10,4 \%$ e $19,5 \%$.

Uma compilação que tratou da humificação de plantas aquáticas vasculares (Bianchini et al. 2004) que considerou $C$. piauhyensis, $N$. indica, E. najas, $S$. cubensis e E. azurea indicou, a exceção de $N$. indica, o predomínio da formação de AF da MOP. No caso dos detritos de $N$. indica houve o predomínio de AF e de AH desde a MOD (Figura 3).

\section{MINERALIZAÇÃO DE SUBSTÂNCIAS HÚMICAS}

Apesardas SHseremconhecidaspela suaresistência à degradação microbiológica, experimentos realizados por vários autores indicam que as substâncias húmicas apresentam grande importância no ciclo do carbono em lagos (Geller 1985, Tranvik \& Höfle 1987, Tranvik 1988). A degradação microbiana das SH é essencial para a circulação do húmus sendo fundamental para
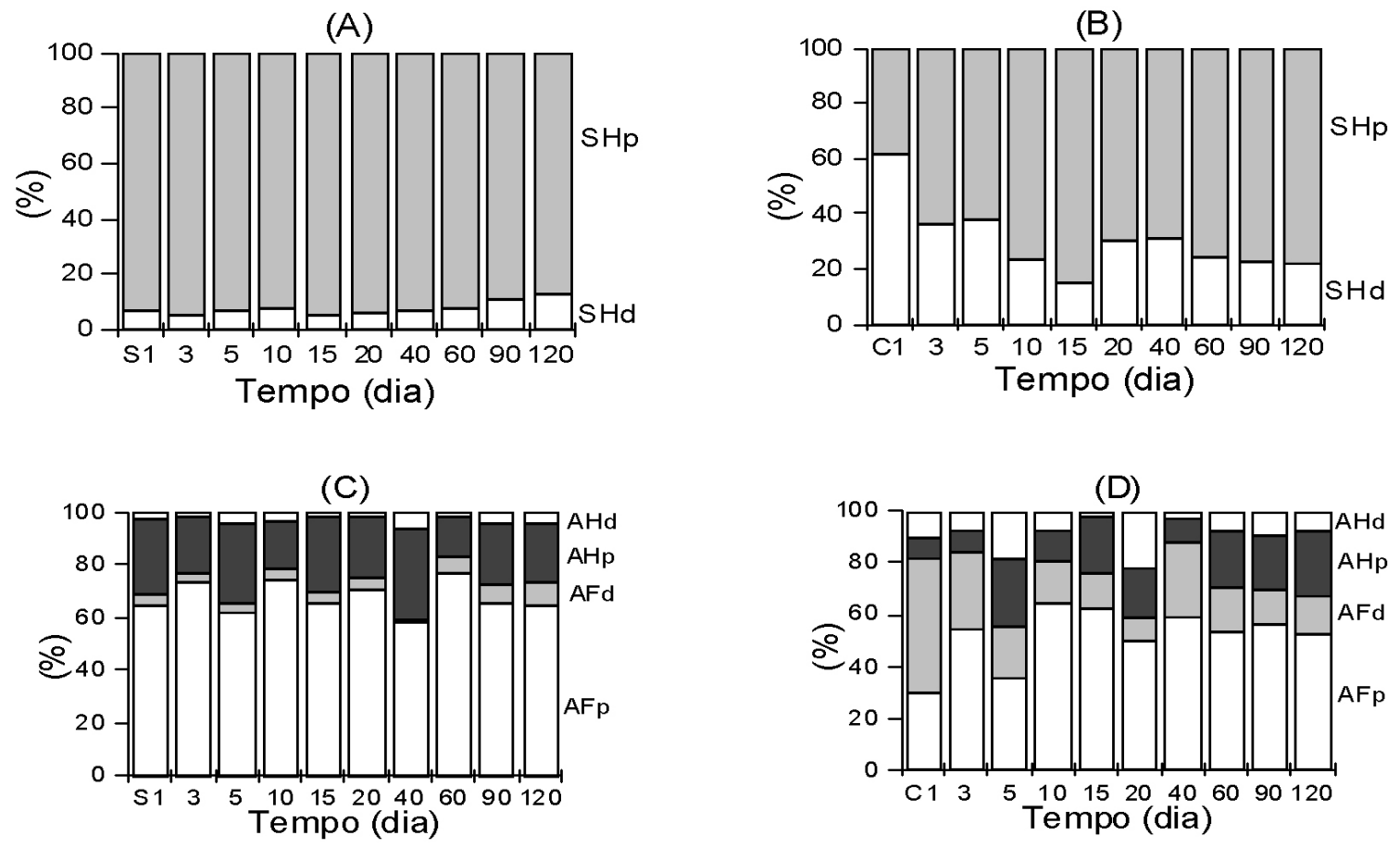

Figura 2. Variação temporal da composição das substâncias húmicas totais extraídas da MOP e da MOD da decomposição de $S$. cubensis (A) e $C$. piauhyensis (B). Variação temporal dos teores de AF e AH da MOP e da MOD originados da decomposição de $S$. cubensis (C) e C. piauhyensis (D) e contribuição relativa de cada fração para o teor de substância húmica total (Cunha \& Bianchini Jr. 2001).

Figure 2. Temporal variation in the relative amounts of humic substances extracted from dissolved and particulate organic matter deriving from the decomposition of $\mathrm{S}$. cubensis $(A) e \mathrm{C}$. piauhyensis (B). Temporal variation of the amounts of AF and AH of dissolved and particulate organic matter deriving form the decomposition of $\mathrm{S}$. cubensis $(C)$ e $\mathrm{C}$. piauhyensis $(D)$ and relative contribution of each fraction to the total bulk of humic substances. From Cunha \& Bianchini Jr, 2001. 


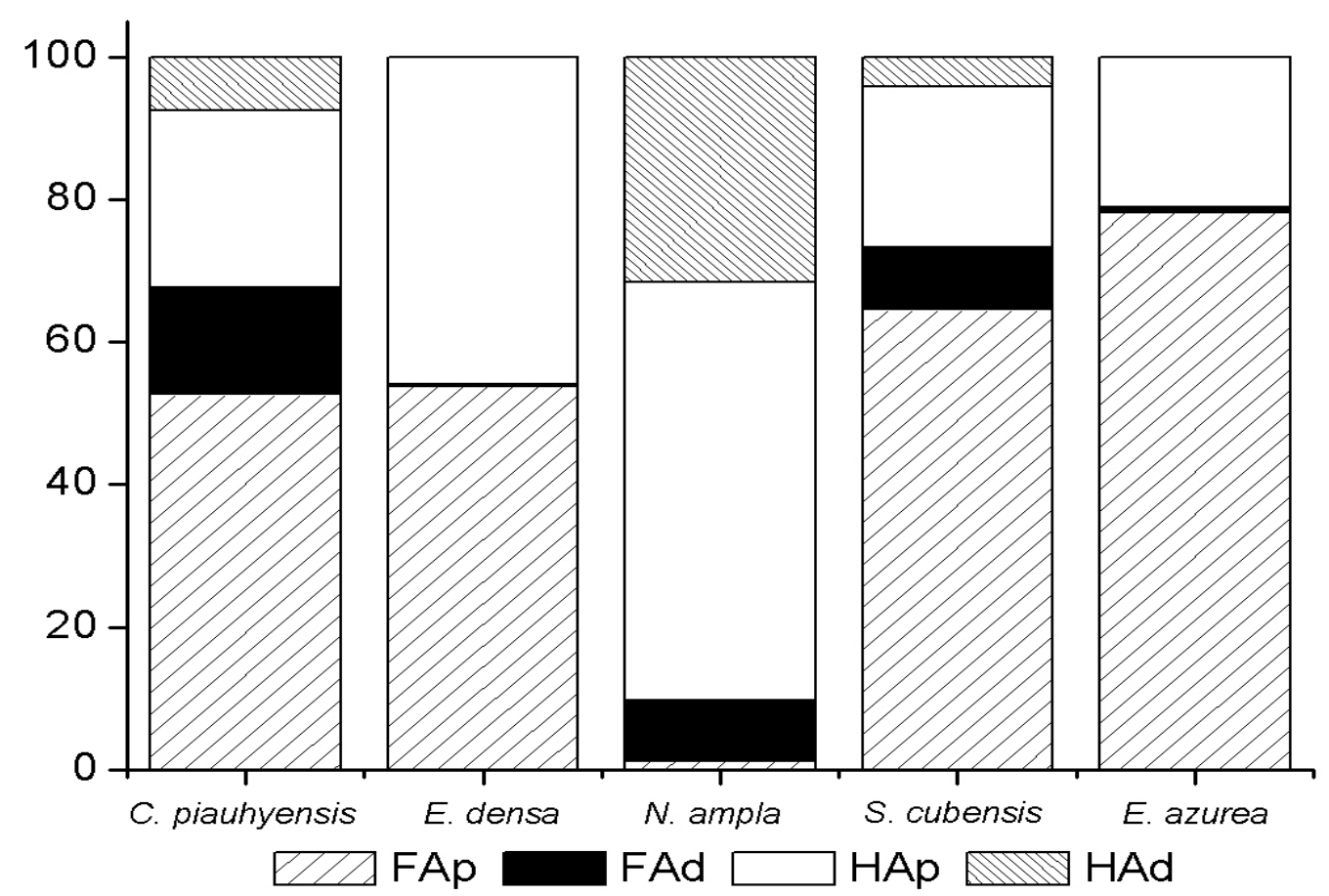

Figura 3. Contribuição dos AF e AH das frações dissolvidas (AFd e AHd) e particuladas (AFp e AHp) durante a decomposição de plantas aquáticas (Bianchini et al. 2004).

Figure 3. Contribution of $A F$ and AH to the dissolved (AFd e AHd) and particulate (AFp e AHp) organic matter fractions from the decomposition of aquatic plants. From Bianchini et al. 2004.

a manutenção do ciclo global do carbono (Carlsson et al. 1998). Bactérias isoladas de lagos húmicos têm apresentado correlações positivas entre o crescimento da biomassa e o conteúdo de compostos húmicos (Hessen 1992). Donderski \& Burkowska (2000) estudaram o metabolismo heterotrófico de bactérias isoladas de lagos sobre $\mathrm{SH}$ e suas frações (AH e AF) isolados da água e do sedimento. A biodegradação de SH por fungos (Cladosporium cladosporioides e Polyporus versicolor) produtores de fenoloxidases também foram reportados em um lago pantanoso (Claus \& Filip 1998). As degradações de AF extraídos de solos foram decorrentes das atividades saprofíticas de 29 tipos de fungos, segundo registro de Strnadová et al. (2004). Por sua vez, o basidiomiceto Collybia dryophila apresentou a habilidade de degradar $\mathrm{AH}$ originados de solos por um sistema enzimático lignolítico (Steffen et al. 2002).

As mineralizações das $\mathrm{SH}$ nos sistemas aquáticos dependem do número e da atividade das bactérias heterotróficas, das frações reativas dos compostos húmicos, da disponibilidade de oxigênio e da temperatura (Coats et al. 2002). Além da oxidação química das substâncias húmicas, oxidações devido às atividades metabólicas dos microrganismos também ocorrem (Golterman 1975). Fatores como temperatura (Antonio \& Bianchini Jr. 2002), grau de refratabilidade dos substratos(Wetzel 1990), nutrientes disponíveis para as atividades dos microrganismos (Amon \& Benner 1996), agentes oxidantes, como oxigênio e aceptores de elétrons inorgânicos e orgânicos (Kristensen \& Holmer 2001) e radiação solar (Anesio et al. 2000) atuam diretamente sobre a decomposição.

Estudos referentes à biodegradação de $\mathrm{SH}$ também indicam a existência de duas frações distintas: uma lábil e uma refratária (Qualls 2004). As SH provenientes da degradação de $S$. cubensis e $C$. piauhyensis constituíram-se de frações heterogêneas do ponto de vista estrutural, apresentando uma parte lábil e uma refratária (Cunha 1999). Estudos referentes à perda de COD provenientes de AF e AH de sedimento, macrófitas aquáticas e MOD em condições aeróbias e anaeróbias sugeriram que a mineralização é mais eficiente em condições oxidativas sendo que esse processo subsidia a formação de biomassa de microorganismos (POC) (Cunha-Santino \& Bianchini Jr. 2002). Experimentos de consumo de oxigênio que contemplaram a degradação aeróbia de $\mathrm{SH}$ indicaram, de maneira geral, que as oxidações dos AF consumiram mais oxigênio ao serem comparadas com as dos $\mathrm{AH}$; esses resultados indicam a complexidade 
estrutural dos AH em resistir a biodegradação e que a mineralização aeróbia dos AF fazem mais pressão sobre a demanda bentônica de oxigênio que os $\mathrm{AH}$ (Cunha-Santino \& Bianchini Jr. 2004). Estudos sobre degradação de $\mathrm{SH}$ em condições anaeróbias demonstraram que esses compostos são utilizados com aceptores de elétron e fonte de energia na assimilação do carbono por bactérias (Coates et al. 2002).

\section{CICLAGEM DAS SUBSTÂNCIAS HÚMICAS - O CASO DA LAGOA DO INFERNÃO (E. E. DE JATAÍ, LUIZ ANTONIO, SP)}

A lagoa do Infernão $\left(21^{\circ} 35^{\prime} \mathrm{S}\right.$ e $\left.47^{\circ} 51^{\prime} \mathrm{O}\right)$ pertence ao sistema de lagoas marginais da bacia do rio MogiGuaçu, situada na região central do estado de São Paulo. É uma das 15 lagoas que recebem proteção oficial da Estação Ecológica de Jataí (2133' a $21^{\circ} 37^{\prime}$ 'S e $47^{\circ} 45^{\prime}$ a $\left.47^{\circ} 51^{\prime} \mathrm{O}\right)$. Une-se ao rio apenas nos períodos de cheia e apresenta, atualmente, a totalidade de sua superfície ocupada por vegetação aquática. Sua região litorânea é dominada, em geral, por macrófitas flutuantes, algumas das quais, com talos estendidos descendentemente até as raízes, fixas nos sedimentos (Mozeto \& Esteves 1986). Considerando a temperatura e o oxigênio dissolvido como fatores controladores da ciclagem de $\mathrm{SH}$ na lagoa do Infernão, o processo de mineralização foi mais efetivo de novembro a abril (Figura 4). Para o AH a mineralização durante os meses mais quentes foi similar independente da disponibilidade de oxigênio no meio. As simulações (Figura 4) indicaram que a ciclagem das $\mathrm{SH}$ é mais rápida em baixas concentrações de oxigênio dissolvido, sendo o mês de fevereiro a época de maior mineralização. Os baixos coeficientes de mineralização dos $\mathrm{AH}$ podem ser explicados pela complexidade e recalcitrância da estrutura molecular e pela especificidade metabólica dos microorganismos. A simulação da variação temporal dos coeficientes de mineralização das SH da lagoa do Infernão sugere que esse processo é lento, e que esses compostos tendem a serem incorporados no sedimento. O rio Mogi-Guaçu apresenta regime unimodal, ou seja, condições potenciais de inundação uma vez ao ano, esse evento geralmente ocorre de dezembro a fevereiro (Ballester \& Santos 2000). A exportação da $\mathrm{SH}$ devido à inundação da planície e a mineralização devido as temperatura mais elevadas são eventos que dominam ao se considerar a ciclagem das SH no ambiente (Cunha-Santino \& Bianchini Jr. 2008).

\section{CONSIDERAÇÕES FINAIS}

Do ponto de vista metabólico a mineralização e a humificação são eventos concorrentes (Figura 5).

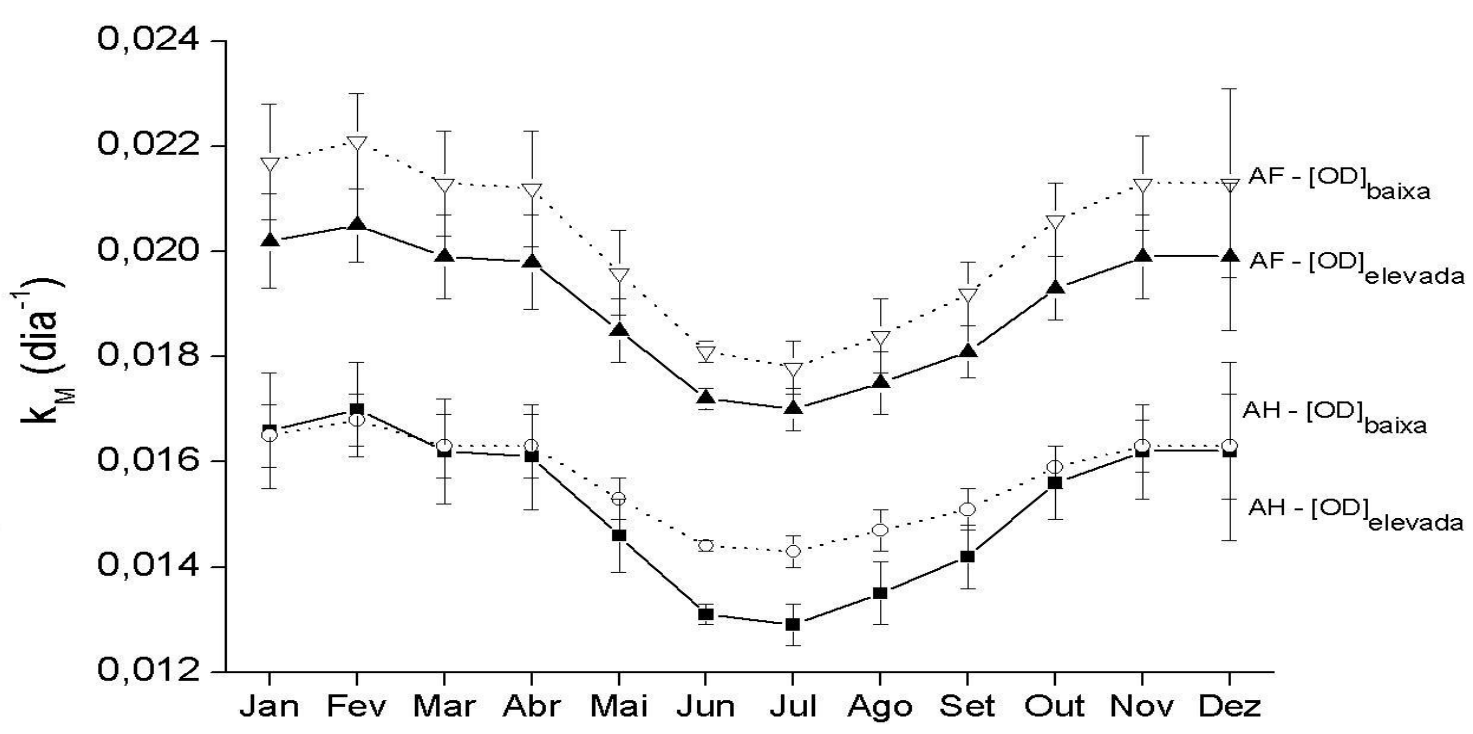

Figura 4. Variação temporal dos coeficientes de mineralização $\left(\mathrm{k}_{\mathrm{M}}\right)$ dos $\mathrm{AF}$ e $\mathrm{AH}$ em condições de baixa e elevada disponibilidade de oxigênio e alta (Cunha-Santino \& Bianchini Jr. 2008).

Figure 4. Temporal variation of the mineralization coefficient $\left(k_{M}\right)$ of $A F$ and AH in low-oxygen and high-oxygen conditions. From Cunha-Santino \& Bianchini Jr. 2008. 
Esses processos são regidos por diferentes funções de força; nesse contexto, a mineralização é dependente, sobretudo da disponibilidade/tipo de aceptores de elétrons e da temperatura; essas duas variáveis interferem diretamente no metabolismo heterotrófico dos microrganismos decompositores. Por outro lado, a humificação prevalece nos meios redutores (ex. brejos, águas intersticiais e subterrâneas; Thurman 1985) e em ambientes onde predominam condições adversas para o catabolismo da microbiota.

Os processos fotodegradativos sobre a MOD, em especial, as SH nos ambientes aquáticos podem aumentar a eficiente heterotrófica no metabolismo do carbono. Na presença de uma fonte contínua e intensa de radiação ultravioleta, a oxidação da matéria orgânica pode ser rápida e eficiente (Achterberg \& Van den Berg 1994). Tal processo consiste na ocorrência de reações químicas que envolvem moléculas que contêm grupos cromóforos (ex. ácidos carboxílicos e estruturas aromáticos) capazes de absorver luz e que podem atuar como fotossensibilizadores (Brezonik 1994). Efeitos positivos do processo fotodegradativo são atribuídos à produção de compostos orgânicos de baixo peso molecular (Bertilsson \& Tranvik 2000), que se tornam facilmente assimiláveis pela atividade microbiana. Wetzel et al. (1995) registraram aumento no crescimento bacteriano utilizando MOD exposta a fotodegradação. Por outro lado, a fotodegradação altera a qualidade da MOD por meio da descoloração das águas (Skoog et al. 1996), aumentando a penetração da luz através da coluna d'água, podendo ampliar os efeitos da radiação solar sobre a biota (Herndl et al. 1997).

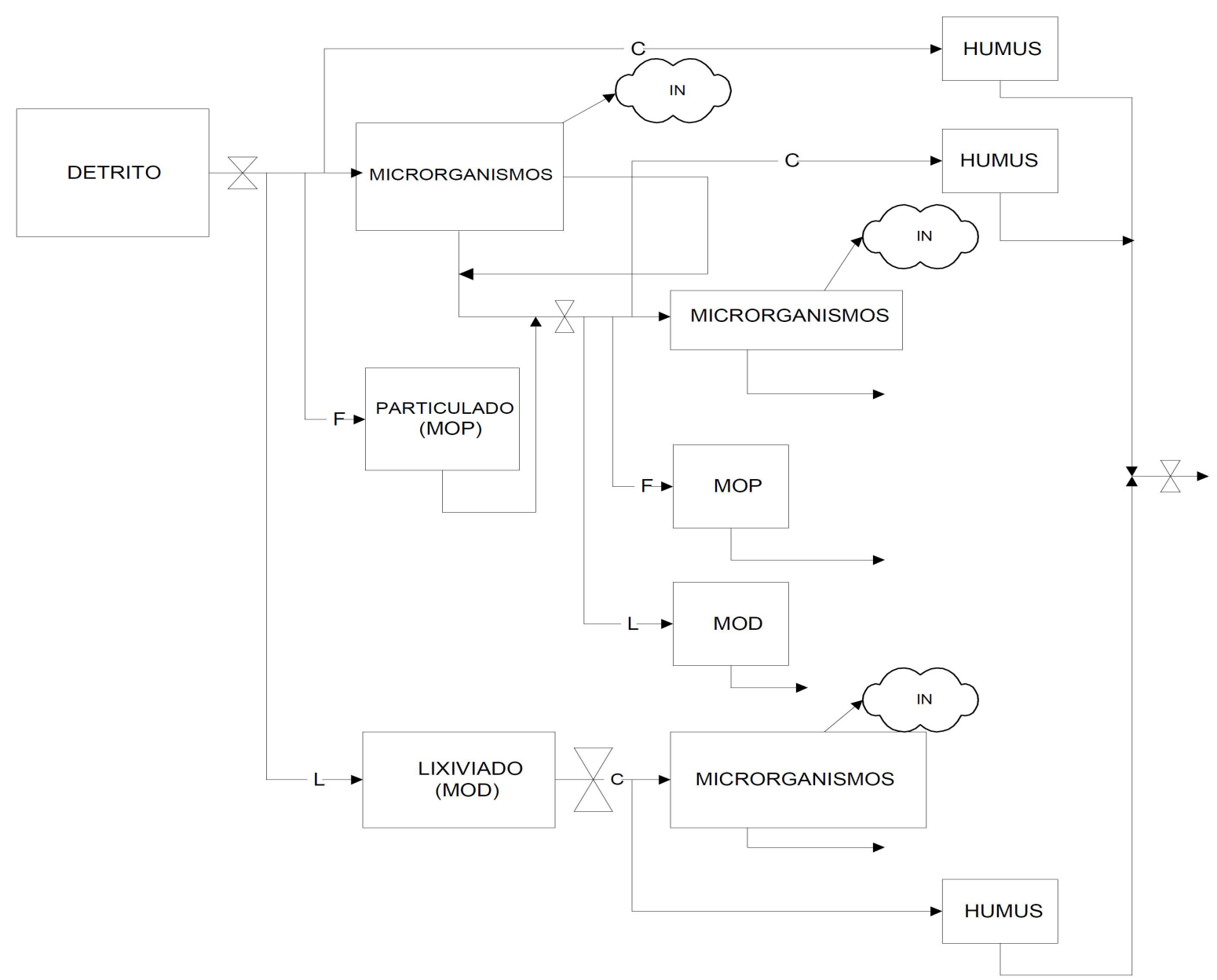

Figura 5. Rotas de humificação e mineralização de detritos. Os três componentes do processo, catabolismo (C), fragmentação (F) e lixiviação (L) alteram a composição química (e.g. a mineralização gerando as formas inorgânicas (IN) e a ressíntese formando microrganismos e húmus) e promovem mudanças físicas do detrito (e.g. redução do tamanho de partícula) e a remoção de compostos solúveis para outros locais (Swift et al. 1979).

Figure 5. Routes to humification and mineralization of organic debris. The three components of the process - catabolism (C), fragmentation (F), and lixiviation (L) - change the chemical composition (e.g. with mineralization generating inorganic forms (IN), and synthesis de novo generating humus and microorganisms), and promote physical changes to debris (e.g. size reduction) and movimentation of soluble matter to other locations (Swift et al. 1979). 
AGRADECIMENTOS: Os autores agradecem a Coordenadoria de Aperfeiçoamento de Pessoal de Nível Superior (CAPES) e Fundação de Amparo à Pesquisa do Estado de São Paulo (FAPESP) pelo financiamento dessa pesquisa (Processo 95/00119-8).

\section{REFERENCIAS}

ACHTERBERG, E.P. \& VAN DEN BERG, C.M.G. 1994. Inline ultraviolet-digestion of natural water samples for tracemetal determination using an automated voltammetric system. Analytical Chimica Acta, 291: 213-232.

AITKENHEAD-PETERSON, J.A.; MCDOWELL, W.H. \& NEFF, J.C. 2003. Sources, production and regulation of allochthonous dissolved organic matter inputs to surface waters. Pp. 25-70. In: S. Findlay \& R.E. Sinsabaugh (eds.). Aquatic Ecosystems: Interactivity of Dissolved Organic Matter. Academic Press, San Diego. 512p.

AMON, R.M.W. \& BENNER, R. 1996. Photochemical and microbial consumption of dissolved organic carbon and dissolved oxygen in the Amazon River system. Geochimica et Cosmochimica Acta, 60: 1783-1792.

ANESIO, A.M.; THEIL-NIELSEN, J. \& GRANÉLI, W. 2000. Bacterial growth on photochemically transformed leachates from aquatic and terrestrial primary producers. Microbial Ecology, 40: 200-208.

ANESIO, A.M.; ABREU, P.C. \& BIDDANDA, B.A. 2003. The role of free and attached microorganisms in the decomposition of estuarine macrophyte detritus. Estuarine, Coastal and Shelf Science, 56: 197-201.

BALLESTER, M.V.R. \& SANTOS, J.E. 2001. Biogenic gases $\left(\mathrm{CH}_{4}, \mathrm{CO}_{2}\right.$ and $\left.\mathrm{O}_{2}\right)$ distribution in a riverine wetland system. Oecologia Brasiliensis, 9: 21-31.

BERTILSSON，S. \& TRANVIK，L.J. 2000. Photochemical transformation of dissolved organic matter in lakes. Limnology and Oceanography, 45: 753-762.

BIANCHINI Jr., I. 1985. Estudos dos processos de humificação de Nymphoides indica (L.) O. Kuntze. Tese de Doutorado. Programa de Pós Graduação em Ecologia e Recursos Naturais da Universidade Federal de São Carlos, São Carlos, Brasil. 285p.

BIANCHINI Jr., I.; CUNHA-SANTINO, M.B.; BITAR, A.L. \& TOLEDO, A.P.P. 2004. Humification of vascular aquatic plants. Pp: 82-84. In: Humic Substances and Soil and Water Environment: proceedings XII International Meeting of IHSS. São Pedro, SP. 763p.
BITAR, A.L. 2003. Mineralização e formação de gases da degradação de Eichhornia azurea Kunth e Egeria najas Planch. Tese de Doutorado. Programa de Pós Graduação em Ecologia e Recursos Naturais da Universidade Federal de São Carlos, São Carlos, Brasil. 118p.

BREZONIK, P. L. 1994. Chemical kinetics and process dynamics in aquatic systems. Lewis, Boca Raton. 754p.

CAMPOS Jr., J.J.F. 1998. Contribuição ao estudo da decomposição de macrófitas aquáticas da lagoa infernão: processo anaeróbio. Dissertação de Mestrado. Programa de Pós Graduação em Ecologia e Recursos Naturais da Universidade Federal de São Carlos, São Carlos, Brasil. 130p.

CARLSSON, P.; EDLING, H. \& BÉCHEMIN, C. 1998. Interactions between a marine dinoflagellate (Alexandrium catenella) and a bacterial community utilizing riverine humic substances. Aquatic Microbial Ecology, 16: 65-80.

COATES, J.D.; COLE, K.A.; CHAKRABORTY, R.; O'CONNOR, S.M. \& ACHENBACH, L.A. 2002. Diversity and ubiquity of bacteria capable of utilizing humic substances as electron donors for anaerobic respiration. Applied and Environmental Microbiology, 68: 2445-2452.

CLAUS, H. \& FILIP, Z. 1998. Degradation and transformation of aquatic humic substances by laccase-producing fungi Cladosporium cladosporioides and Polyporus versicolor. Acta Hydrochimica et Hydrobiologica, 26: 180-185.

CUNHA, M.B. \& BIANCHINI Jr., I. 1994. Formação e mineralização de compostos húmicos. Relatório de Pesquisa. UFSCar/FOMENTO, São Carlos. 36p.

CUNHA, M.B. 1999. Mineralização de compostos húmicos da lagoa do Infernão (Luiz Antonio). Dissertação de Mestrado. Programa de Pós Graduação em Ecologia e Recursos Naturais da Universidade Federal de São Carlos, São Carlos, Brasil. 141p.

CUNHA, M.B. \& BIANCHINI Jr., I. 2001. Formação de compostos húmicos a partir da degradação de Scirpus cubensis e Cabomba piauhyensis. Acta Limnologica Brasiliensia, 13: $35-43$.

CUNHA-SANTINO, M.B. \& BIANCHINI Jr., I. 2002. Humic substance mineralization in a tropical oxbow lake (São Paulo, Brazil). Hydrobiologia, 468: 33-43.

CUNHA-SANTINO, M.B. \& BIANCHINI Jr., I. 2004. Oxygen uptake during mineralization of humic substances from Infernão lagoon (São Paulo, Brazil). Brazilian Journal of Biology, 64: 583-590. 
CUNHA-SANTINO, M.B. \& BIANCHINI Jr., I. 2008. Carbon cycling potential from Utricularia breviscapa decomposition in a tropical oxbow lake (São Paulo, Brazil). Ecological Modelling, 218: 375-382.

D'ARIENZO, M.C.F. 1989. Efeitos dos produtos de decomposição de Sphagnum sp sobre a decomposição de Mayaca fluviatilis. Dissertação de Mestrado. Programa de Pós Graduação em Ecologia e Recursos Naturais da Universidade Federal de São Carlos, São Carlos, Brasil. 130p.

DONDERSKI, W. \& BURKOWSKA, A. 2000. Metabolic Activity of heterotrophic bacteria in the presence of humic substances and their fractions. Polish Journal of Environmental Studies, 9: 267-271.

FARIA, B.M. \& ESTEVES, F.A. 2001. Dissolved organic carbon in two Brazilian coastal lagoons: sources and utilization for heterotrophic bacteria. Oecologia Brasiliensis, 9: 57-64.

FERNANDEZ-JOVER, D.; SANCHEZ-JEREZ, P.; BAYLESEMPERE, J.; CARRATALA, A. \& LEON, V.M. 2007. Addition of dissolved nitrogen and dissolved organic carbon from wild fish faeces and food around Mediterranean fish farms: implications for waste-dispersal models Journal of Experimental Marine Biology and Ecology, 340: 160-168.

GARNIER-SILLAM, É.; HARIYENTO, S. \& BOUREZGUI, Y. 1999. Humic substances in peats (Sumatra, Indonesia). Analusis, 27: 405-408.

GELLER, A. 1985. Degradation and formation of refractory DOM by bacteria during simultaneous growth on labile substrates and persistent lake water constituents. Schweizerische Zeitschrift Fur Hydrologie, 47: 27-44,

GOLTERMAN, H.L. 1975. Physiological Limnology. Amsterdam: Elsevier Scientific Publishing Company, 480p.

GROSS, E.M. 2003. Allelopathy of aquatic autotrophs. Critical Reviews in Plant Science, 22: 313-339.

GRUBER, D.F.; SIMJOUW, J.-P.; SEITZINGER S.P. \& TAGHON, G.L. 2006. Dynamics and characterization of refractory dissolved organic matter produced by a pure bacterial culture in an experimental predator-prey system. Applied Environmental Microbiology, 72: 4184-4191.

HAYES, M.H.B. \& SWIFT, R.S. 1978. The chemistry of soil organic colloids. Pp. 179-318. In: D. J. E. GREENLAND \& M.H.B. HAYES (eds.). The Chemistry of Soil Constituents. John Wiley \& Sons, Chichester. 469p.

HERNDL, G.J.; BRUGGER, A.; HAGER, S.; KAISER, E.; OBERNOSTERER, REITNER, B. \& SLEZAK, D. 1997. Role of
ultraviolet-B radiation on bacterioplankton and the availability of dissolved organic matter. Vegetatio, 128: 43-51.

HESSEN, D.O. 1992. Dissolved organic carbon in a humic lake: effect on bacterial production and respiration. Hydrobiologia, 229: 115-123.

HURST, H.M. \& BURGES N.A. 1967. Lignin and Humic Acids. Pp. 260 - 286. In: A.D. MCLAREN \& G.H. PETERSON (eds.). Soil Biochemistry. Marcel Dekker, New York. 509p.

JACKSON, G.A. 1989. Simulation of bacterial attraction and adhesion to falling particles in aquatic environment. Limnology and Oceanography, 34: 514-530.

KRISTENSEN, E. \& HOLMER, M. 2001. Decomposition of plant materials in marine sediment exposed to different electron acceptors $\left(\mathrm{O}_{2}, \mathrm{NO}_{3}\right.$, and $\left.\mathrm{SO}_{4}\right)$, with emphasis on substrate origin, degradation kinetics, and the role of bioturbation. Geochimica Cosmochimica Acta, 65: 419-433.

KLAVINS, M.; RODINOV, V. \& DRUVIETIS, I. 2003. Aquatic chemistry and humic substances in bog lake in Latvia. Boreal Environment Research, 8: 113-123.

KREVS, A.; KOREIVIENE, J.; PASKAUSKAS, R. \& SULIJIENE, R. 2007. Phytoplankton production and community respiration in different zones of the Curonian lagoon during the midsummer vegetation period. Transitional Water Bulletin, 1: $17-26$.

LINDELL, M.; GRANÉLI, W. \& TRANVIK, L.J. 1995. Enhanced bacterial growth in response to photochemical transformation of dissolved organic matter. Limnology and Oceanography, 40: 195-199.

MANN, C.J. \& WETZEL, R.G. 1996. Loading and utilization of dissolved organic carbon from emergent macrophytes. Aquatic Botany, 53: 61-72.

MEGONIGAL, J.P.; HINES, M.E. \& VISSCHER, P.T. 2004. Anaerobic metabolism: linkages to trace gases and aerobic processes. Pp. 317-424. In: W.H. Schlesinger (ed.). Biogeochemistry. Elsevier-Pergamon, Oxford. 588p.

MOZETO, A.A. \& ESTEVES, F.A. 1986. Ecologia de lagoas marginais. Ciência Hoje, 5: 73.

MULDERIJ, G.; MAU, B.; DONK, E.V. \& GROSS, E. 2007. Allelopathic activity of Stratiotes aloides on phytoplankton towards identification of allelopathic substances. Hydrobiologia, 584: 89-100.

MÜNSTER, U.; SALONEN, K. \& TULONEN, T. 1999. Decomposition. Pp. 225-264. In: J. Keskitalo \& P. Eloranta 
(eds.). Limnology of humic waters. Backhuys Publishers, Leiden. 284p.

OCHIAI, M.; NAKAJIMA, T. \& HANDA, T. 1980. Chemical composition of labile fractions in DOM. Hydrobiologia, 71: 95-97.

PICOLlO, A.; COZZOLINO, A.; CONTE, P. \& SPACCINI, R. 2000. Polimerization of humic substances by an enzyme-catalyse oxidative coupling. Naturwissenschaften, 97: 391-394.

PURVINA, S.; BÉCHEMIN, C.; BALODE, M.; GRZEBYK, D. \& MAESTRINI, S.Y. 2008. Influence of inorganic nutrients and dissolved organic matter on the growth of cyanobacteria Microcystis aeruginosa isolated from the Gulf of Riga. Acta Universitatis Latviensis, 745: 63-74.

QUALLS, R.G. 2004. Biodegradability of humic substances and other fraction of decomposing leaf litter. Soil Science Society of America Journal, 68: 1705-1712.

RAND, G.M.; WELLS, P.G. \& MACARTY, L.S. 1995. Introduction to aquatic toxicology. Pp. 3-66. In: G.M. Rand, (ed.). Fundamentals of aquatic toxicology - Effects, environmental fate, and risk assessment. 1125p.

RASPOPOV, I.M.; ADAMEC, L. \& HUSAK, S. 2002. Influence of aquatic macrophytes on the littoral zone habitats of the Lake Ladoga, NW Russia. Preslia, 74: 315-321.

SAUNDERS, G.W. 1980. Organic matter and decomposers. Pp. 341-392. In: E.D. LE CREN \& R.H. LOWE-McCONNELL (eds.). The functioning of Freshwater Ecosystems. Univ. Press, Cambridge. 628p.

SKOOG, A.; WEDBORG, M. \& FOGELQVIST, E. 1996. Photobleaching of fluorescence and the organic carbon concentration in a coastal environment. Mar. Chem., 55: $333-345$.

STEFFEN, K.T.; HATAKKA, A. \& HOFRICHTER, M. 2002. Degradation of humic acids by the litter-decomposing Basidyomicete Collybia dryophila. Applied and Environmental Microbiology, 68: 3442-3448.

STEINBERG, C.E.W. 2003. Ecology of humic substances in freshwaters (First Edition). Springer, Berlin. 440p.

STEVENSON, F.J. 1982. Humus Chemistry. Wiley, New York. 443p.

STRNADOVÁ, V.; HRSELOVÁ, H.; KOLARÍK, M. \& GRYNDLER, M. 2004. Response of saprotrophic microfungi degrading the fulvic fraction of soil organic matter to different $\mathrm{N}$ fertilization intensities, different plant species cover and elevated atmospheric $\mathrm{CO}_{2}$ concentration. Folia Microbiologica, 49: 563-568.
SWIFT, M.J.; HEAL, D.W. \& ANDERSON, J.M. 1979. Studies in Ecology. Decompositions in Terrestrial Ecossistems. Blackwell, Oxford. 371p.

TATE, R.L. 1995. Soil Microbiology. Wiley \& Sons, New York. 398p.

TOLEDO, A.P.P. 1976. Estudo das Interações de ions Cúpricos com os Ácidos Húmicos e Fúlvico. Tese de Doutorado. Universidade de São Paulo, São Carlos, Brasil. 165p.

TRANVIK, L.J. \& HÖFLE, M. 1987. Bacterial growth in mixed cultures on dissolved organic carbon from humic and clear waters. Applied Environmental Microbiology, 53: 482-488,

TRANVIK, L.J. 1988. Availability of dissolved organic carbon for planktonic bacteria in oligotrophic lakes of different humic content. Microbial Ecology, 16: 311-322.

TRANVIK, L.J. 1992. Allochthonous dissolved organic matter as an energy source for pelagic bacteria and the concept of microbial loop. Hydrobiology, 229: 107-114.

TRANVIK, L.J. 1994. Effects of colloidal organic matter on the growth of bacteria and protists in lake water. Limnology and Oceanography, 39: 1276-1285.

TULONEN, T. 2004. Role of allochthonous and autochthonous dissolved organic matter (DOM) as a carbon source for bacterioplankton in boreal humic lakes. Master Dissertation, University of Helsinki, Faculty of Biosciences, Department of Biological and Environmental Sciences, Aquatic Sciences, Hydrobiology, Lammi Biological Station. 32p.

THURMAN, E.M. \& MALCOLM, R.L. 1981. Preparative isolation of aquatic humic substances. Environmental Science and Technology, 15: 465-466.

THURMAN, E.M. 1985. Organic Geochemistry of Natural Waters. Nijhoff/Junk Po., Netherlands. 497p.

WETZEL, R.G. 1990.Detritus, macrophytes and nutrient cycling in lakes. Memorie dell Instituto Italianodi Idrobiologia Dott Marco de Marchi, Pollanza, 47: 233-249.

WETZEL, R.G. 1995. Death, detritus and energy flow in aquatic ecosystems. Freshwater Biology, 33: 83-89.

WETZEL, R.G. 2001. Limnology - Lake and reservoir ecosystems (Third Edition). Academic Press, San Diego. 1006p.

Submetido em 14/09/2009.

Aceito em 28/11/2009. 